\title{
Inference, Circularity, and Begging the Question
}

\author{
MATTheW William MCKeON
}

Department of Philosophy

Michigan State University

503 S. Kedzie Hall, East Lansing, MI

mckeonm@msu.edu

\begin{abstract}
I develop a syntactic concept of circularity, which I call propositional circularity. With respect to a given use of an argument advanced as a statement of inference for the benefit of a reasoner $\mathrm{R}$, if the direct and indirect premises $\mathrm{R}$ would have to accept in order to accept the conclusion includes the conclusion, then the collection of premises is propositionally circular. The argument fails to display a type of inference that $\mathrm{R}$ can perform. Appealing to propositional circularity, I articulate a sufficient condition for a use of an argument to beg the question, highlighting why question-begging is a defect.
\end{abstract}

Résumé: Je développe un concept syntaxique de la circularité, que je nomme la circularité propositionnelle. En ce qui concerne une utilisation donnée d'un argument avancé comme un énoncé d'une inférence pour le bénéfice d'un raisonneur $R$, si les prémisses directes et indirectes que $R$ doit accepter pour accepter la conclusion comprennent la conclusion, alors l'ensemble des prémisses est propositionnellement circulaire. L'argument ne parvient pas à exprimer un type d'inférence que $R$ peut effectuer. Je fais appel à la circularité propositionnelle pour décrire une condition suffisante pour un emploi d'un argument circulaire, en soulignant pourquoi un tel argument est défectueux.

Keywords: Inference, statements of inference, indirect premise, circularity, begging the question

\section{Introduction}

Working closely with Woods and Walton (1975), I develop a syntactic concept of circularity, which I call propositional circularity. With respect to a given use of an argument advanced as a statement of inference for the benefit of a reasoner $\mathrm{R}$, if the collection of direct and indirect premises $\mathrm{R}$ would have to accept in order to accept the conclusion includes the conclusion, then the collection is propositionally circular and the argument so used fails to display a type of inference that $\mathrm{R}$ can perform. Appealing to Sanford (1981) and Jackson (1987), I use the concept of propositional circularity to articulate a sufficient condition for 
the use of an argument to beg the question, highlighting why question-begging is a defect. Roughly, if an argument advanced as a statement of inference fails to display the inference it advertises because the collection of direct and indirect premises is propositionally circular, then the argument so used begs the question. This characterization motivates thinking that questionbegging is not an inferential fault, and makes it hard to see why it should be treated as an epistemic defect. Furthermore, it is not obvious that begging the question is a fallacy, understood as a mistake in reasoning. This point has been made elsewhere (e.g., Hazlett (2006), Woods (2008)), but I believe its plausibility is enhanced by considering begging the question as nullifying the role of an argument as a statement of inference. Unfortunately, the role that the notion of inference plays in an account of begging the question has been neglected in the literature. My elucidation of a syntactic circularity condition that causes an argument to fail as a statement of inference highlights the connection between the notion of inference and begging the question in a way that advances a pragmatic approach to explicating begging the question.

I begin by discussing the notion of inference as it figures in the use of an argument as a statement of inference. Then I introduce the concept of propositional circularity and explain why all propositionally circular arguments fail as statements of inference. Next, I use the analysis of the equivalence and dependence conceptions of circularity in Woods and Walton (1975) to develop the notion of propositional circularity so that it applies to the collection of direct and indirect premises at play in an arguer's use of an argument as a statement of inference. An indirect premise for the conclusion of an argument used as a statement of inference is a proposition that an addressee accepts as support for a premise or would have to accept as support for a premise in order to accept the conclusion. A collection of direct and indirect premises is propositionally circular just in case it includes the proposition expressed by the conclusion. I use this notion of propositional circularity to elucidate the fallacy of begging the question. I'll propose that the use of an argument as a statement of inference is question-begging if the associated collection of direct and indirect premises is propositionally circular. Finally, I consider criticisms derived from Biro (1977) and Wilson (1988) and then conclude. 


\section{Mckeon}

\section{Statements of inference and propositionally circular arguments}

For purposes of this paper, I follow Woods, Irvine, and Walton and use the expression "argument" in what they call its narrow sense according to which an argument is a sequence of propositions one of which is the argument's conclusion, the rest of which are the argument's premises $(2004$, p. 2; for development of this definition, see my 2013). Salmon remarks that the evaluation of an inference requires that the conclusion and the evidence from which it is drawn are stated. "When the evidence is stated, we have the premises of an argument. When the conclusion is stated, it becomes the conclusion of that argument. The statement of the inference is thus an argument" (Salmon, 1984, p. 9). An argument displays a reasoner R's inference only if $R$ accepts the conclusion on the basis of R's acceptance that the premises are true and that they support the conclusion. ${ }^{1}$ In this paper, I take acceptance to entail belief: to accept that $p$ is to believe that $p$ with a certain degree of certainty. An argument advanced as a statement of inference is an argument the arguer uses in order to display an inference from its premise(s) to conclusion.

\footnotetext{
${ }^{1}$ Woods and Walton $(1975$, p. 110$)$ point out that it may be necessary for an argument to represent the temporal order of premise-beliefs in order for it to accurately display a reasoner's inference. For example, suppose I learn that Paige is at home or she is at work without knowing her whereabouts. Upon arriving at home, I discover that she is not at home. I infer that she is at work. Suppose that we portray the inference as follows.
}

[1] Paige is at work or at home

[2] Paige is not at home

$\therefore$ [3] Paige is at work

In order for [1] to represent the belief at work in the inference or must be read intensionally and not truth-functionally. But then [1] and [2] do not accurately represent the belief set that forms the basis of my inference. Belief that [2] commits me to the falsehood of the second disjunct of [1], while my belief that [1] commits me to being non-committal about the truth-value of the second disjunct. The argument misrepresents the inference unless it depicts the inference diachronically. Following Woods and Walton, one way to do this is to assign the appropriate temporal indicators to the premises, e.g., I've known [1] that Paige is at work or at home, I now discover [2] that Paige is not at home, so [3] Paige is at work. In what follows, I ignore this complication. 
It is standard in epistemology to take this basing relation to be a kind of causal relation. ${ }^{2} \mathrm{R}$ 's acceptance that the (presumed) truth of the premises supports the conclusion causes $\mathrm{R}$ to accept the conclusion, and, therefore, the premises become the reasons for which $\mathrm{R}$ believes the conclusion. Consider the following classically-valid argument.

\section{Obama is President}

$\therefore$ The moon is made of cheese or it is not the case that the moon is made of cheese

It is doubtful that one can infer the conclusion from the premise, because it is hard to imagine a reasoner $\mathrm{R}$ accepting the conclusion on the basis of R's acceptance of the premise. Since the truth of the premise is obviously irrelevant to the truth of the conclusion, it seems unlikely that belief that the premise is true can be causally relevant to belief that the conclusion is true, i.e., it is doubtful that the premise can be a reason for which somebody believes the conclusion. In sum, an argument displays a reasoner R's inference at time $t$ only if at $t \mathrm{R}$ 's acceptance that the (presumed) truth of the premises supports the conclusion causes $\mathrm{R}$ to accept the conclusion, i.e., at $t$ the premises become the reasons for which $\mathrm{R}$ accepts the conclusion.

If a reasoner $\mathrm{R}$ infers the conclusion from the premises of an argument, then R's acceptance that the premises are true and that they support the conclusion causes R's acceptance of the conclusion by virtue of either generating R's belief that the conclusion is true or by virtue of increasing R's credulity in her

\footnotetext{
${ }^{2}$ E.g., (Boghossian, 2012, p. 4), "S's inferring from $p$ to $q$ is for $\mathrm{S}$ to judge $q$ because $\mathrm{S}$ takes the (presumed) truth of $p$ to provide support for $q$." To be sure, there is more to reasoning than causation: not every causal process through which, say, one of your beliefs causes a second is inference. I maintain that a necessary condition of inference is that an inferrer R's acceptance that the (presumed) truth of the premises supports the conclusion causes R to accept the conclusion. The development of a theory of inference, which tells us what more there is to reasoning than 'mere' causation, is beyond the scope of this paper. Like Boghossian, I am focusing on inference as a relation between beliefs and as, "reasoning that is person-level, conscious and voluntary, not sub-personal, sub-conscious and automatic" (pp. 2-3). Furthermore, I focus on the generative and confirmative aspects of inference according to which the inferrer accumulates beliefs and confirms beliefs held prior to the inference. Hence, my focus on inference is narrower than that of others such as Harman (1986) who views it as a mechanism for a "reasoned change in view", in which you start off with some beliefs and then, after a process of reasoning, end up either adding new beliefs, or(-inclusive) subtracting old ones.
} 


\section{Mckeon}

conclusion-belief held prior to performing the inference. For purposes of this paper, this is my understanding of how an inferrer's premise-beliefs causally matter to her conclusion-belief. Inferences can be generative: they can be sources for new beliefs. Such inferences are events of belief formation: one comes to explicitly believe the conclusion on the basis of explicitly believing the premises. ${ }^{3}$ Other inferences are merely confirmatory: the premise-beliefs buttress or increase one's conviction in something already explicitly believed. My formulation of the distinction between generative and confirmatory inferences borrows from (Audi, 2011, pp.182-183).

That an argument displays more than one inference does not entail that they are tokens of the same type. For example, suppose that Kelly and Paige both believe [1] that Beth is in her bedroom only if she is home, and [2] that Beth is not at home. Suppose further that each infers from her two beliefs [3] that Beth is not in her bedroom. I take the following argument to display their inferences.

[1] If Beth is in her bedroom, then she is at home

[2] Beth is not at home

$\therefore$ [3] Beth is not in her bedroom

Suppose that Kelly and Paige just completed courses in formal logic. Kelly's inference is a token of a modus-tollens type of inference. However, Paige never learned modus tollens in her logic class. She reasons as follows. By contraposition, she infers from [1] that Beth is not in her bedroom if Beth is not at home. From this and [2] she infers [3] by modus ponens. Kelly's and Paige's inferences are of different types, because they draw the conclusion from the premises in different ways. Unlike Kelly's direct inferential route to the conclusion, Paige's inference from [1] and [2] to [3] is mediated by the inferential steps described

\footnotetext{
${ }^{3}$ I borrow the notion of an explicitly held belief from (Harman 1986, pp.1214), who uses it to underwrite his Clutter Avoidance Principle (CAP): One should not clutter one's mind with trivialities. CAP, which counters the claim that one's beliefs should be closed under logical consequence, presupposes that "beliefs are explicitly 'represented' in the mind in the sense that these representations play the important role in perception, thought, and reasoning that we think beliefs play" (p. 12). According to Harman, one believes something explicitly if one's belief in that thing involves an explicit mental representation whose content is the content of that belief (p.13). In this paper, I consider inference as a relation between beliefs (see note labove) where the inferrer explicitly believes the initial premises of the inference.
} 
above. Paige's and Kelly's inferences share inferential content, but differ in regard to inferential process.

Clearly, no argument displays a reasoner R's inference unless it displays a type of inference a token of which $\mathrm{R}$ performed. An argument displays a type of inference only if a reasoner could infer the conclusion from the premises. In other words: if an argument displays a type of inference, then the argument has the potential to display a reasoner's generative or confirmative inference.

There are two elements of an inference: inferential process and inferential content (Audi, 2011, p. 177). Suppose that I infer that my wife is home from my belief that her car is in the driveway. One element of this inference is the mental process of drawing the conclusion from the premise. We call this mental episode of reasoning the inferential process. Another element of my inference is the collection of propositions that are the conclusion and premise(s) of my inference. This collection, which we call the inferential content, indicates what is inferred from what. The inferential content includes the propositional content of the premise-beliefs of the inference and its conclusion. Clear$1 y$, inferential process is distinct from inferential content; the former is a mental episode, the latter is a collection of propositions.

When an argument displays a reasoner's inference, it displays that part of the inferential content consisting of the initial premise-basis and the conclusion-belief. In order for an argument to display a type of inference its premises and conclusion must state propositions that could be part of the inferential content of a reasoner's inference. If it is not possible for a reasoner to perform the mental act of drawing the conclusion from the premises of an argument, then the propositions expressed by the argument cannot serve as the content of an inference and that argument fails to displays a type of inference. To illustrate, consider propositionally circular arguments, which fail to display a type of inference because they lack the potential to display a reasoner's inference.

If the conclusion of an argument expresses the identical proposition expressed by a premise, then I'll say that the argument is propositionally circular. The following two arguments are propositionally circular. 


\section{Mckeon}

Beth is at work

$\therefore$ Beth is at work

\section{Sam Clemens lived in Hartford, Connecticut}

\section{$\therefore$ Mark Twain lived in Hartford, Connecticut}

The conclusion and premise of the top argument state the same proposition in the same way, and the conclusion and premise of the bottom argument state the same proposition in different ways. Sinnott-Armstrong (1999, p. 175) distinguishes between weakly and strongly circular arguments. The top argument is strongly circular since the premise expresses the same proposition in the same way as the conclusion. The bottom argument is weakly circular because one of its premises is used to express the same proposition as its conclusion. Both types of circularity are instances of propositional circularity. The following two arguments are not propositionally circular.

This sentence is a premise

$\therefore$ This sentence is a premise

$\sim($ Beth is at work $\mathrm{v}$ Beth is at home)

$\therefore \sim$ Beth is at work $\& \sim$ Beth is at home

Although the conclusion of the top argument repeats the conclusion word for word, they express different propositions. Even though the conclusion and premise of the bottom argument are logically equivalent, they express different propositions (only the conclusion expresses a conjunction).

No propositionally circular argument displays a type of inference. ${ }^{4}$ If I infer a conclusion from the premise(s) of an argument, then my acceptance that the premises are true is a cause of my acceptance that the conclusion is true. So, if a reasoner $\mathrm{R}$ could infer the conclusion of a propositionally circular argument from the premises, then a premise-belief and a conclusion-belief of R's inference are identical and R's acceptance that a proposition $p$ is true causes $\mathrm{R}$ 's acceptance that $p$ is true.

\footnotetext{
${ }^{4}$ This does not contradict Sinnott-Armstrong's observation that weakly circular arguments can be informative (1999, p. 176). For example, the above weakly circular argument can be informative to an addressee who, prior to the presentation of the argument, was unaware that Sam Clements is Mark Twain, and, was, therefore, unaware that by virtue of believing the second premise she believed the conclusion. Below on p. 321, I highlight how an argument can be propositionally circular without going wrong.
} 
However, it is impossible that $\mathrm{R}$ has come to believe that $p$ on the basis of believing that $p$. Even if one thinks that circular causal chains are somehow possible, they seemed ruled out when it comes to accounting for the cognitive support premisebeliefs provide for the conclusion-belief of an inference.

If one performs a generative inference, then one comes to explicitly believe the conclusion on the basis of explicitly believing the premises. Since it is impossible to come to explicitly believe something on the basis of explicitly believing it, circular generative inferences are impossible. Other inferences are merely confirmatory: the premise-beliefs buttress or increase one's conviction in something already believed. It is unlikely that a belief can bear this relation to itself (e.g., the degree of my credence that $p$ can't causally arise from my degree of credence that $p$ ). This rules out circular confirmative inferences. More generally, if I infer $q$ from $p$ then my belief that $p$ explains, at least in part, why I believe $q$. For no proposition $q$, does the fact that I believe $q$ explain why I believe that $q$. This is true even if $q$ is self-evident (if there are such propositions), for even in such cases it is the nature of $q$ rather than the fact that you believe $q$ that explains why you believe that $q$.

Given that a circular inference requires that a proposition be inferred from itself, there are no circular inferences. Those who claim otherwise may not be distinguishing between inferences and arguments as I do here. For example, Jacquette uses the expression "inference" to designate arguments. I take this to be the operative meaning of the expression when he describes, $\mathrm{P}-\mathrm{P}$, as a question-begging pattern of inference (1993, p. 318). However, the meaning of "inference" as used by other advocates of the possibility of circular inferences is less clear, and, in some cases, seems to designate episodes of reasoning (e.g., Wilson, 1988, pp.44, 45). Denying that there are circular inferences leaves open the option of accepting that circular reasoning is possible, as long as such reasoning is not construed as an inferential process. Unfortunately, reasoning is often characterized in terms of inferential process. ${ }^{5}$

\footnotetext{
${ }^{5}$ For example, see (Walton 1990). Walton characterizes reasoning as a process of inferring conclusions from statements in two steps. First, he defines an inference as the "use of a rule or warrant to link some proposition (statements) with others. The conclusion is the proposition toward which the inference moves. The premises are the beginning propositions from which the inference starts. Thus, an inference links the premises to the conclusion, and it always has a direction-proceeding from the premises to the conclusion" (p.402). Next, he claims that reasoning can be understood in terms of inferential process when reasoning is understood as "the making or granting of as-
} 
That the presentation of an argument increases an addressee's credence of the conclusion does not suffice for her to have inferred it from the premises. To illustrate, I borrow from Pinto (2001, p.37). Imagine a situation in which an argument is advanced as an invitation to inference and its presentation causes assent to its conclusion but in which the addressee did not make an inference from the premises to its conclusion. For example, the argument is actually too complicated for the addressee to follow, but worn down by its length and caught up by the arguer's charm, the addressee's resistance to the conclusion disappears. Pinto asks, "Would we count this as a case in which the addressee was persuaded by the argument to accept its conclusion?" I say, "No", in agreement with Pinto who responds: "Caused, yes. But not, I maintain, persuaded" (p.37). On my view, this is because the increase in the addressee's certainty of the conclusion is not a result of her performing an inference from the premises to conclusion.

Confirmatory and generative inferences transmit conviction from premises to conclusion. Therefore, that I infer the conclusion of an argument presented to me from its premises requires a certain initial epistemic asymmetry between premises and conclusion. I must initially be more certain of the premises than I am of the conclusion; otherwise there will be nothing to transmit. Obviously, no argument of the form, $p / \therefore p$, can transmit conviction from its premise to conclusion; I cannot be more cer-

sumptions called premises (starting points) and the process of moving toward conclusions (end points) from these assumptions by means of warrants. A warrant is a rule or frame that allows the move from one point to the next point in the sequence of reasoning "(p. 403). However, the characterization of inference is too weak since the process of moving towards a conclusion can be a derivation of it from premises by means of warrants without being an inferential process. For example, my logic students are asked to deduce (using the class deduction rules) who had to be at the pub from the following information: Tom, Mike, or Frank was at the pub Friday night; Mike was not there unless Frank was there; and Tom was at the pub only if another brother was there. Students engaging this problem may reason by virtue of "moving towards a conclusion" from the given information by means of deduction rules, which serve as "warrants". However, since the students know that the scenario is fictitious, it is implausible to think it necessary that a student infer and, therefore, accept that Frank was at the pub Friday night by virtue of deriving this from the given information. At best, Walton's characterization of inference articulates a necessary condition for inference, since one may move towards a conclusion in the sense of deriving it from given assumptions by means of warrants without the derivation representing an inferential process. Plausibly, derivations are forms of reasoning. If so, then, since derivations can be circular, circular reasoning is possible even if circular inferences are not. 
tain of the premise than I am of the conclusion. Therefore, such arguments cannot display inferences.

To avoid misunderstanding, I am not denying that the use of a propositionally circular argument may legitimately engender an addressee R's certainty of the conclusion. Propositional circularity is a formal property that is non-evaluative. Therefore, an argument can be propositionally circular without going wrong (Wilson, 1988, p.50, makes a similar point). For example, I agree with Sorenson $(1991$, p. 248) that the following argument is rationally persuasive.

$\underline{\text { Some arguments are written in black ink }}$

$\therefore$ Some arguments are written in black ink

The argument fails to display a type of inference: a person cannot accept the conclusion on the basis of accepting the premise. However, a person who doubted the conclusion could come to accept it by considering the argument because it exemplifies the conclusion. The reason offered for the conclusion is not the proposition stated by the premise, but the argument qua illustration of the conclusion. Whether or not the propositional circularity of an argument is problematic depends on how the argument is being used. In particular, since, as noted above, no propositionally circular argument can serve as a statement of inference, such an argument cannot be successfully used to justify its conclusion in a way that requires it to display a type of inference. For example, Sinnott-Armstrong distinguishes between two senses of justification: audience and arguer (Sinnott-Armstrong, 1999, p. 181).

An arguer who uses an argument for the purpose of audience justification uses it to show the audience that the premises are reasons for the audience that justify their acceptance of the conclusion. We may say that an argument advanced as a statement of inference for the purpose of audience justification invites the audience to perform a token of the type of inference that the argument purports to display (see Pinto (2001) for discussion of the use of arguments as invitations to inference). An argument advanced as a statement of inference for the purpose of arguer justification is used to report the arguer's justification. Here an arguer uses an argument to display a type of inference a token of which was performed by the arguer, without extending an invitation to the audience to perform a token of the stated inference type. Such an argument is good only if the arguer's inference is legitimate. Clearly, the successful use of an argument 
advanced as a statement of inference for the purposes of audience and arguer justification requires that it display a type of inference, a token of which the audience and arguer can perform given their beliefs prior to the presentation of the argument. Sorenson's argument cannot function as an instrument of arguer or audience justification construed as above by virtue of the fact that it fails to display a type of inference.

\section{The equivalence and dependence conceptions of circularity}

In their discussion of the fallacy of begging the question, Woods and Walton (1975) characterize two basic types of circularity, the equivalence and dependence conceptions of circularity, and discuss various instantiations of them. In this section, I use the equivalence and dependence conceptions of circularity to articulate a circularity condition that rules out an argument's potential to display an inference performable by its addressees. More specifically, I develop the notion of propositional circularity so that it reflects aspects of both the equivalence and dependence conceptions of circularity. This will make propositional circularity relevant to explaining why an argument fails to display an inference its addressees can perform even though the argument proper is not propositionally circular. I start by focusing on the concept of equivalence circularity, which Woods and Walton characterize as follows.

According to the equivalence conception (as we shall say), an argument is said to be circular where the conclusion is tacitly or explicitly assumed as one of the premisses, that is, where the conclusion is equivalent, or even identical, to one of the premisses (Woods and Walton, 1975, pp.107-108).

Equivalence-circularity is solely a function of the relationship between propositions expressed by an argument's components, i.e., the proposition expressed by the conclusion is equivalent or identical to the proposition expressed by a premise. As a formal criterion of circularity, inspection of the propositions expressed by premises and conclusion suffices to determine whether an argument is equivalence-circular. Propositional circularity instantiates the equivalence conception of circularity, since the conclusion and premise of a propositionally circular argument state the identical proposition. 
Woods and Walton articulate the following conditions of equivalence circularity (1975, p. 109).

\section{Equivalence Conditions}

(CQ) The conclusion is equivalent to some premissconjunct.

(CI) The conclusion is identical to some premissconjunct.

(CQE) (For a) to know that a premiss-conjunct is true is (for a) to know that the conclusion is true, and vice versa.

(CP) One has to state the conclusion in order to state some premiss conjunct, and vice versa.

Each condition appeals to the notion of a premiss conjunct, which Woods and Walton characterize as follows. "Where a premiss has the form ' $\mathrm{P}_{1} \& \mathrm{P}_{2} \& \ldots \& \mathrm{P}_{\mathrm{k}}$ ' $\{\mathrm{k} \geq 1\}$ and where $\mathrm{P}$ is the set $\left\{\mathrm{P}_{1}, \mathrm{P}_{2}, \ldots, \mathrm{P}_{\mathrm{k}}\right\}$ then a premiss-conjunct is any subset of $\mathrm{P}$. In other words, a premiss conjunct is simply a premiss or conjunctive component of a premiss" (1975, note 9, p. 125). I take (CI) and (CP) to be the strongest conditions: each entails the other two, and neither (CQ) nor (CQE) entail (CI) or (CP). If one of (CI) and (CP) obtains, then the other must obtain, i.e., if the conclusion is identical to some premise-conjunct then one has to state the conclusion in order to state that premise conjunct, and, following Woods and Walton, vice versa.

The rationale for appealing to conjunctive components of a premise in spelling out the equivalence conception is not obvious. After all, the argument,

Kelly lives in Concord and she works in Bristol. $\therefore$ Kelly lives in Concord,

is not equivalence-circular $a$ la the broad conception since the conclusion is neither identical nor equivalent with the premise. Yet, it seems to satisfy each of the equivalence conditions. The argument is not propositionally circular either since the first conjunct of the conjunction is not identical with the conjunction. Perhaps, the motivation for appealing to conjunctive components of premises in explicating equivalence-circularity is that a sentence used to state a conjunctive proposition states each conjunct of that proposition. Hence, the above single-premise argument is circular for the exact same reason as the below two- 
premise argument is circular: the conclusion and a premise state an identical proposition.

Kelly lives in Concord

She works in Bristol

$\therefore$ Kelly lives in Concord.

This suggests that all arguments that are instances of the following patterns are equivalence-circular.

$$
p, q / \therefore p \& q, \quad p \& q / \therefore p, \quad p \& q / \therefore q
$$

I say that such arguments display types of inferences. By virtue of explicitly believing the premise(s) one does not thereby explicitly believe the conclusion and so one could accept the conclusion on the basis of accepting the premise(s). I maintain that a sentence on a given use of it expresses at most one proposition, not a plurality of propositions. On my view, the appeal to conjunctive components of premises in explicating equivalencecircularity is unmotivated. A sentence that expresses a conjunctive proposition does not express the propositions expressed by each conjunct. The sentence, "Kelly lives in Concord and she works in Bristol", expresses one proposition, not two. Consequently, one does not explicitly believe that Kelly lives in Concord by virtue of explicitly believing that Kelly lives in Concord and she works in Bristol. These beliefs differ because they have different propositional contents. So, it is possible for a reasoner $\mathrm{R}$ at a time $t$ to accept the conclusion of the first argument above because $\mathrm{R}$ accepts the premise. On my view, the first argument above, but not the second, displays a type of inference. I don't favor understandings of equivalence circularity that suggests otherwise.

Some argumentation theorists may complain that I am being too fastidious about propositional identity in judging whether an argument is propositionally circular. Botting (2011, pp.33-34), for example, maintains (i) that if one asserts that $p \& q$, one thereby asserts that $p$ and asserts that $q$ and (ii) that if one asserts that $p$ and one asserts that $q$, one thereby asserts that $p \& q$. Since Botting thinks that in order for a purported argument to qualify as an argument the arguer must not assert the conclusion in asserting the premises, he maintains that the above patterns are not patterns of arguments. Given that a premise and conclusion of an argument are not asserted by an arguer unless she explicitly believes them, Botting's contention suggests that by ex- 
plicitly believing the premise(s) of an instance of one of the above patterns one thereby explicitly believes the conclusion. I disagree. It is worth explaining why since I take intuitions about the contents of assertions seriously as evidence of what is explicitly believed. I advance three considerations; the first two aim to discredit (i), the third is directed against (ii).

The assertion of a conjunction is not a plurality of assertions of the conjuncts, because the content of the assertion of a conjunction is essentially structured by the connective. For example, a conjunction can be asserted and denied. Suppose that I deny a conversant's erroneous assertion that Kelly lives in Ohio and does not live in the Buckeye State. Am I denying a pair of assertions? I think not. To deny the conjunction is not to deny each conjunct. Furthermore, it is far from obvious that my denial of what is asserted is necessarily a denial of either conjunct. Suppose both that I have no idea where Kelly lives and that I deny the assertion because I know that Ohio is the Buckeye State. I am not in an epistemic position to either deny that Kelly lives in Ohio or deny that she doesn't live in the Buckeye State. It seems that what I am denying in this scenario is the conjunction, not the pair of conjuncts. One may say that by denying that Kelly lives in Ohio and does not live in the Buckeye State, I am asserting the negation: it is not true that she lives in Ohio and doesn't live in the Buckeye State. Since what is asserted is what I deny and I deny a conjunction, it is a conjunction that is asserted, not a collection of assertions of the conjuncts. I now turn to the second consideration against (i).

Suppose a conversant makes the following assertions. [1] Kelly and Paige have been away travelling. [2] Kelly went to Mexico. [3] Paige went to Puerto Rico and she says it is 80 degrees there. There is something wrong with a naked assertion of 'she tells me that it's 80 degrees there' without something for the anaphora to be anchored in. The 'and' in [3] directs us look to the first conjunct to secure reference of the anaphora in the second conjunct. If asserting a conjunction is merely asserting each conjunct, then it shouldn't matter from the point of view of assertion if you switched the two conjuncts in [3] around. But again, there is something very strange from the point of view of assertion if you switched the above two sentences around.

Finally, against (ii), consider the lottery paradox. I enter a one-million-ticket lottery. I believe that $t_{1}$ won't win, $t_{2}$ won't win, etc. But I don't believe that ( $\mathrm{t}_{1}$ won't win \& $\mathrm{t}_{2}$ won't win \& $\ldots \& \mathrm{t}_{1,000,000}$ won't win). Hence, for each $\mathrm{t}_{\mathrm{n}}$, I am willing to as- 
sert that $t_{n}$ won't win, but I am not willing to assert the conjunction of what they assert.

Perhaps, my case can be advanced by appealing to the notion of implicitly believing something. Here I borrow from (Harman, 1986, pp. 13-14). Recall that one believes something explicitly if one's belief in that thing involves an explicit mental representation whose content is the content of that belief. One believes something only implicitly if it is not explicitly believed, but, for example, is easily inferable from one's explicit beliefs. For example, given that one explicitly believes that the earth has exactly one moon and one does not explicitly believe that the earth does not have two moons, that the earth does not have three moons, and so on, then one implicitly believes these propositions since one can easily infer any of them from one's explicit belief that the earth has exactly one moon.

Given that one explicitly believes that MSU is in East Lansing and explicitly believes that $\mathrm{U}$ of $\mathrm{M}$ is in Ann Arbor and doesn't explicitly that MSU is in East Lansing and $U$ of $M$ is in Ann Arbor, it is plausible to think that one implicitly believes the conjunction given one's grasp of the inferential properties of 'and'. That the argument,

MSU is in East Lansing

$\underline{\mathrm{U}}$ of $\mathrm{M}$ is in Ann Arbor

$\therefore$ MSU is in East Lansing and $\mathrm{U}$ of M is in Ann Arbor,

displays a type of inference highlights the fact that inference is a means for making explicit one's implicit beliefs.

In sum, propositional circularity is solely a function of the relationship between an argument's components. As a formal criterion of circularity, an argument's equivalence-circularity does not vary from one context of use to another. Therefore, if an argument fails to displays a type of inference because it is equivalence-circular, then the equivalence of premise and conclusion must be spelled out in a way that nullifies the argument's capacity to display an inference in every situation of use. Propositional circularity, unlike the equivalence conditions given above, is an explication of the equivalence conception of circularity that makes such circularity relevant to whether an argument has the potential to display an inference.

If we drop the notion of a premise-conjunct from the statement of the equivalence conditions and replace "premiss conjunct" with premise and use "accept" instead of "know" in (CQE), then we get the following. 
$\left(\mathrm{CQ}^{*}\right)$ The conclusion is equivalent to some premise.

$\left(\mathrm{CI}^{*}\right)$ The conclusion is identical with some premise.

(CQE*) (For a) to accept that a premiss is true is (for a) to accept that the conclusion is true, and vice versa.

$\left(\mathrm{CP}^{*}\right)$ One has to state the conclusion in order to state some premise, and vice versa.

I'll ignore $\left(\mathrm{CQ}^{*}\right)$ since only $\left(\mathrm{CI}^{*}\right),\left(\mathrm{CQE}^{*}\right)$, and $\left(\mathrm{CP}^{*}\right)$ rule out the possibility of an argument stating a type of inference. $\left(\mathrm{CI}^{*}\right)$ is a statement of propositional circularity. Since (CI*) entails $\left(\mathrm{CQE}^{*}\right)$ and $\left(\mathrm{CP}^{*}\right)$, treating $\left(\mathrm{CI}^{*}\right)$ as basic allows us to explain why $\left(\mathrm{CQE}^{*}\right)$ and $\left(\mathrm{CP}^{*}\right)$ obtain. For example, with respect to an argument that satisfies $\left(\mathrm{CI}^{*}\right)$, since the conclusion is identical with a premise, (for a) to accept that a premiss is true is (for a) to accept that the conclusion is true, and vice versa. Furthermore, one has to state the conclusion in order to state some premise, and vice versa. The syntactic conception of circularity (CI*) grounds the epistemological one $\left(\mathrm{CQE}^{*}\right)$ and the semantic one $\left(\mathrm{CP}^{*}\right)$.

Woods and Walton remark that,

the problem with explicating the equivalence conception is that while strict identity of premiss and conclusion is too narrow a criterion, capturing only the obvious cases, equivalence is too wide a criterion, attributing circularity to many arguments which plainly are not circular (1975, p.108).

I agree. For example, dependence circularity can nullify an argument's potential to display an inference performable by addressees even though the conclusion is not strictly identical with a premise. The narrowness of $\left(\mathrm{CI}^{*}\right)$-circularity renders it insufficient to capture a circularity condition that makes arguments used as statements of inference incapable of stating an inference that every addressee can perform. I now turn to the dependence conception of circularity with the aim of developing the concept of propositional circularity so that it brings more into play than just the components of arguments.

Arguments circular according to the dependence conception are those where the conclusion is presupposed by a premise or where some premise actually rests on the conclusion, so that in order to accept the premise one must accept the conclusion (Woods and Walton, 1975, p. 108). What follows are the explications of the dependence conception of circularity given by Woods and Walton (1975, p. 109), amended to make them uni- 
form with my reformulation of the equivalence conditions. I replace "premise-conjunct" with "premise" in the statement of each condition.

\section{Dependency Conditions}

(CD) The conclusion entails some premise.

(CDE) In order to know that some premise is true, $a$ must know that the conclusion is true.

(CM) There is some premise that can be known to be true only by inference from the conclusion.

(CM1) There is some premise that can be known to be true only by inference from the conclusion in conjunction with a (possibly empty) set of additional statements (with the exception that the premise must not be known to be true by inference from these other statements alone).

If an argument is $\left(\mathrm{CI}^{*}\right)$-circular, then $(\mathrm{CD})$ and $(\mathrm{CDE})$ obtain. I am uncomfortable with (CM) and (CM1) as conditions of circularity. Typically, arguments are used in situations according to which there are many ways to come to know their premises. This diminishes the relevance of (CM) and (CM1) as determinants of begging the question (here I echo Sanford, 1988, p.35 and Wilson, 1988, p.43). I'll focus on CDE. Since it is acceptability of premises and conclusion that is at play in inference, I reformulate $\mathrm{CDE}$ as,

$\left(\mathrm{CDE}^{*}\right)$ in order to accept that some premise is true, $a$ must accept that the conclusion is true.

Two ways to ground the modal in $\left(\mathrm{CDE}^{*}\right)$ are as follows.

(1) The premise and conclusion express the identical proposition.

(2) The conclusion is $a$ 's only reason for which $a$ believes some premise.

If either (1) or (2) obtains for a given argument, then $\mathrm{CDE}^{*}$ obtains, i.e., if either obtains, then in order for a target reasoner $a$ to accept some premise a must accept the conclusion. Note that conditions (1) and (2) may diverge. To illustrate, I borrow an example from Sinnott-Armstrong. 
Imagine a lawyer who presents strong evidence for his client's innocence, but whose closing argument is simply, 'My client is innocent, because she is.' The lawyer is not just repeating the conclusion for emphasis or suggesting that it is obvious. He is trying to justify the conclusion (Sinnott-Armstrong, 1992, p. 109).

Since the lawyer's argument is propositionally circular, (1) obtains. However, (2) does not if we suppose that the lawyer's reason to believe the premise is independent of his belief in the conclusion.

The dependence-circularity of an argument turns on the relationship between the conclusion and an addressee's basis for accepting a premise and accepting that the premises support the conclusion. An addressee R's basis for accepting a premise and accepting that the premises support the conclusion are not required to be components of the argument proper. To illustrate, suppose that I accept that Beth is at work if Beth is not at home, because I accept that she is at work. When asked about Beth's whereabouts, I express the following argument as a statement of my inference(s).

[1] Beth is at work if Beth is not at home. [2] She is not at home since [3] her car is not in the garage. So, [4] she is at work.

This dependence-circular argument fails to display my inference: a premise rests on the conclusion since I accept [1] because I accept [4]. However, the argument is not propositionally circular, since the conclusion is not identical with any of [1]-[3]. The concept of propositional circularity can be broadened beyond ( $\left.\mathrm{CI}^{*}\right)$-circularity by appealing to an addressee's indirect premises for accepting the conclusion. A reason for which I accept a premise that directly supports the conclusion is my indirect premise for the conclusion. By virtue of supporting a premise $\mathrm{P}$ that is a reason for the conclusion, a premise for $\mathrm{P}$ indirectly supports the conclusion. According to the above scenario, [3] and [4] serve as indirect premises for the conclusion. Since the conclusion ([4]) is an indirect premise, it is impossible for me to infer the conclusion from the premises offered directly in support of the conclusion.

An arguer who advances an argument as a statement of inference aims to invite the addressees to perform the inference that the argument purports to display or aims to merely display the arguer's inference. Let's call such reasoners, target reason- 
ers, i.e., reasoners targeted by the argument. Relative to each use of an argument as a statement of inference there is a collection $\mathrm{C}$ of direct and indirect premises that target reasoners accept or would have to accept in order to accept the conclusion if they are to perform the inference the argument purports to display. If $\mathrm{C}$ includes the conclusion, then $\mathrm{C}$ is propositionally circular and consequently the argument fails to display an inference every target reasoner can perform.

Relative to the use of an argument A advanced in a situation as a statement of inference for the benefit of a target reasoner $\mathrm{R}$, if the relevant collection $\mathrm{C}$ of direct and indirect premises is propositionally circular, then for $\mathrm{R}$ to accept a premise (indirect or otherwise) is for $\mathrm{R}$ to accept the conclusion. The propositional circularity of $\mathrm{C}$ blocks the potential of $\mathrm{A}$ to display an inference that $\mathrm{R}$ can perform. This condition of circularity reflects the equivalence conception by being syntactic and it reflects the dependence conception by virtue of bringing into play indirect premises, which are not components of the argument.

Bringing indirect as well as direct premises into play makes the condition of propositional circularity sufficient for $\left(\mathrm{CQE}^{*}\right)$ and $\left(\mathrm{CDE}^{*}\right)$. Suppose that I advance an argument as a statement of inference and the collection of direct and indirect premises is propositionally circular. In such a situation, a premise (direct or otherwise) and the conclusion express the same proposition, and, therefore, both $\left(\mathrm{CQE}^{*}\right)$ and $\left(\mathrm{CDE}^{*}\right)$ must obtain.

\section{Begging the question}

I propose that the use of an argument as a statement of inference begs the question if the associated collection of direct and indirect premises that the target reasoners would have to accept in order to accept the conclusion includes the conclusion. The defect of begging the question is pragmatic: the arguer fails in her attempt to state an inference performable by every target reasoner. I now elaborate by drawing on the debate between Biro and Sanford. Biro remarks that Sanford believes that it is more helpful to think of the fallacy of begging the question in terms of inferences rather than arguments understood solely in terms of their form and content (1984, p. 240). It is worth clarifying the role the notion of inference plays in Sanford's account of begging the question in order to distinguish the fallacy as a defect of the use of an argument as a statement of inference and not as a defect of inference performed by a target reasoner. 
Sanford identifies two conditions relevant to the evaluation of an inferrer S's inference of the form ' $p$, therefore $q$ ' (Sanford, 1981, p. 149).

(1) Constitutive Conditions: (i) $p$; (ii) $p$ implies $q$.

(2) Epistemic Conditions: (i) $\mathrm{S}$ believes that $p$; (ii) $\mathrm{S}$ believes that $p$ implies $q$; (iii) $\mathrm{S}$ does not have either of these beliefs because he already believes that $q$.

Note that the constitutive and epistemic conditions of inference differ in that a token inference can fail (1i) and (1ii): a premisebelief of an inference may be false and the conclusion of an inference may not be supported by the premise(s). However, no token inference can fail an epistemic condition. If an "inferrer" $\mathrm{S}$ doesn't believe $p$, doesn't believe that $p$ implies $q$, or $\mathrm{S}$ has one of these beliefs because S already believes $q$, then S can't infer $q$ from $p$ since S's acceptance that $q$ can't be based on S's acceptance that $p$. In such a case, $\mathrm{S}$ can't infer $q$ from $p$ since $\mathrm{S}$ 's acceptance of $p$ can't cause S's acceptance of $q$. Unlike conditions 1(i-ii), 2(i-iii) constrain the possibility of an argument with $p$ as its premise and $q$ as its conclusion stating an inference, legitimate or otherwise, performable by $\mathrm{S}$.

According to Sanford, an argument begs the question if it violates 2(iii). He remarks that,

[a] purported inference that contains its own conclusion as a premiss begs the question. It also violates the epistemic condition that an inferrer not believe a premiss because he already believes the conclusion. I would say that an argument that violates this condition begs the question whether or not it contains a premiss, or premiss-conjunct, that is identical to the conclusion, so long as the person giving the argument purports to give at least one of his reasons for having some degree of confidence in the conclusion (Sanford, 1981, p. 150).

I take it that when Sanford refers to a "purported inference" he is not speaking about an inference, but an argument advanced as a statement of inference. It is unfortunate that Sanford does not spell out the relevance of (2iii) as an evaluative criterion of inference to begging the question given that he distinguishes between inferences and arguments and holds that it is only arguments that can beg questions. If an argument advanced as a statement of inference fails to display an inference performable by a target reasoner $\mathrm{R}$, then the premises can't constitute R's reasons for having some degree of confidence in the conclusion. 


\section{Mckeon}

The argument cannot function as a statement of R's inference, and if so advanced, it will fail to fulfill this function. This is not an issue of $\mathrm{R}$ performing a defective inference. Rather, it is an issue of an argument failing to fulfill its alleged purpose as a statement of R's inference. Since the possibility of an inference being performed by a reasoner is a separate matter from whether that inference is legitimate, it is misleading to characterize conditions such as 2(i-iii) that constrain the possibility of inference as conditions that constrain the legitimacy of inference. In short, 2(i-iii) do not speak to the evaluation of inference; rather they are criteria that constrain the possibility of an argument displaying a target reasoner's inference. This observation is in sync with Biro's criticism of Sanford.

Biro objects to Sanford's epistemic condition 2(iii), because it fails as an evaluative criterion of inference.

Even if [one] believes the premisses of [an] argument because [italics are Biro's] he already believes the conclusion, it does not follow that we are faced with a case of a question-begging argument. The notion of an argument's begging the question surely has as little to do with what causes someone to hold certain beliefs as with in what temporal order he comes to acquire them. Of course, we could construe "believes because" as "has reasonable grounds for believing", but only on pain of begging the question ourselves. We are supposed to be explicating what "generating reasonable belief" means and to give criteria for saying when the belief generated is or is not reasonable (Biro, 1977, p.262).

I agree that what causes someone to believe a premise is irrelevant to whether an inference stated by an argument is a means for generating reasonable belief. Again, epistemic condition 2(iii) is not relevant to the evaluation of inference. However, this motivates a criticism of Sanford's account of begging the question only if we take begging the question to be a defect of inference rather than a defect of a given use of an argument as a statement of inference.

Sanford gives an example of a question-begging use of an argument used, in the terminology of this paper, as an instrument of arguer justification where the arguer believes a premise only because he believes the conclusion.

I come from the library to the philosophy department office. I go into the back room to get some more typing paper. It turns out that Jones is there working the mimeo- 
graph machine. When I return to the outer office a colleague comes in and asks where he can find Jones. I produce the following bit of argumentation: Well, he is either at the library or in the back room. I just came from the library, and he wasn't there. So he must be in the back room (1981, p.148).

Sanford remarks that this use of the argument is a sham because the arguer is not giving his reasons for believing the conclusion despite advertising otherwise (1981, p. 149). Later on the same page he says that this is an example of a sham inference because " the statement designated as the conclusion is not inferred from the statements designated as premises. There is no inference unless someone infers something, unless something is inferred." Indeed, since the collection of direct and indirect premises that the arguer accepts includes the conclusion, it is propositionally circular and, therefore, the argument fails to display an inference performable by the arguer. The argument used as above does not represent the arguer's inferential route to the conclusion. This echoes Jackson's analysis of many apparently circular arguments as instances of "misleading advertising" because they have argumentative implicatures that mislead the audience about the nature of the arguer's evidence (Jackson, 1987, p. 107). The use of the argument is a sham in Sanford's scenario because the arguer advertises herself as having evidence of a certain kind for the conclusion, when in fact she does not have evidence of that kind.

Sanford's and Jackson's views here motivate a pragmatic view of the fallacy of begging the question as an issue of an argument failing to fulfill its alleged purpose as a statement of a target reasoner's inference. A use of an argument advanced as a statement of inference is question-begging if the collection of direct and indirect premises is propositionally circular. For a given use of an argument $\mathrm{A}$ as a statement of inference, if the collection of direct and indirect premises is propositionally circular, then A fails to display an inference performable by every target reasoner. To suppose otherwise is to erroneously think that circular inferences are possible.

Some may find it surprising that Sanford's discussion of the fallacy of begging the question motivates a pragmatic approach since it is typically said that he provides a (subjective) epistemological account of the fallacy (e.g., see Biro and Siegel, 2006, p.95; Walton, 2006, p.237; Wilson, 1988, p.38). Ritola, 2003, p.1, refers to Sanford's account of the fallacy as a doxastic analysis by virtue of Sanford's analysis of the fallacy in terms of the 
actual beliefs of the arguer (pp.1,3). However, it is by virtue of this feature of Sanford's account that others refer to it as a subjective epistemological account of the fallacy. What my discussion of Sanford highlights is that inferences do not beg questions, arguments used as statements of inference do. It is misguided to explain the defect of a question-begging argument in terms of the performance of a fallacious inference. ${ }^{6}$

Hazlett thinks that the epistemic conception of questionbegging must be given in terms of reasoning processes and not arguments for "it is clear that reasoning processes and not arguments are the proper objects of epistemic evaluation" (Hazlett, 2006 , p. 345). He offers the following as an epistemic characterization of question-begging: an argument begs the question when one would be proceeding in an epistemically vicious way if one were to engage in the reasoning represented by it (Hazlett, 2006, p.347). I take the idea here to be that believing the conclusion of a question-begging argument on the basis of the premises is one way that one might perform poorly epistemically. This disqualifies my account as an epistemic characterization of begging the question. Arguments that beg the question fail as statements of inference, and so they do not capture reasoning when used in a question-begging way, if "reasoning" is understood inferentially. Since begging the question is a defect of uses of arguments and not of inferences, it is not a ratiocinative flaw. That begging the question is not an inferential fault is a point defended in Hazlett (2006) and Woods (2008).

Clearly, an argument that displays a type of inference could be used in a situation so that even though the relevant collection of direct and indirect premises that a target reasoner accepts in order to accept the conclusion includes the conclusion the argu-

${ }^{6}$ For example, Lippert-Rasmussen (2001) tells us that given that a reasoner R's inferential route to a premise of a question-begging argument goes through its conclusion, R's inference from the premise(s) to its conclusion is fallacious, because it violates an epistemic condition of reasonable inference. He remarks that,

one should not infer a conclusion from premises one accepts (or rejects) only because one accepts (or rejects) that conclusion. Here the increase in one's degree of confidence in the truth of the conclusion stems from irrationality: One reaches the conclusion by way of a fallacious inference (2001, p. 137).

Of course, what needs explaining is how one can "infer" the conclusion from a premise that one accepts only because one accepts the conclusion. To explain the defect of a question-begging argument in terms of one reaching the conclusion by way of a fallacious inference is the wrong way to go given the impossibility of circular inferences. 
ment nevertheless has the potential to generate reasonable belief in the conclusion. In such a situation, Biro thinks that the argument does not beg the question. To illustrate, consider Sanford's oft-discussed Twardowski-situation.

...There is a bylaw that restricts club membership to those who have attended the University of Texas. Moreover, this bylaw is operative; it explains why the club has no members who did not attend the University of Texas. None of this is kept secret. You could discover it easily if you tried. But you have not tried and no one has told you. You are ignorant of the bylaw. You have, however, chatted with each club member from time to time over the years. You know who all of the club members are. You have learned, from each of them, that he attended the University of Texas. Your belief that all club members attended the University of Texas is based on your belief that Twardowski attended the University of Texas (Sanford, 1988, p.35).

I'll refer to the following as the Twardowski argument.

All the members of the club attended the University of Texas.

Twardowski is a member of the club.

$\therefore$ Twardowski attended the University of Texas.

If I advance the Twardowski-argument in the above situation as a statement of my inference, then, since I use the conclusion as an indirect premise, the argument fails to display my inference and so is question begging. However, Biro thinks that the argument so used in this situation does not beg the question, since the existence of the bylaw makes it the case that the premises are knowable, or at least reasonably believable, independently of (that is to say, without relying on or appealing to) the conclusion (Biro and Siegel, 2006, p. 91). That is, the argument states a type of inference a token of which could, if performed in the above situation, justify belief in the conclusion. So, in the above situation the type of inference stated by the Twardowski-argument could generate reasonable belief in the conclusion. For this reason, Biro thinks that the argument does not beg the question in the Twardowski situation.

According to Biro, an argument used in a given situation begs the question by virtue of the fact that some premise of the argument cannot be known without knowing the conclusion, because the conclusion serves as the only basis for accepting it, or 
it can be reached only by an inference from the conclusion (Biro, 1977, pp. 265-66). Biro maintains that an argument used in a given situation is epistemically serious only if it displays a type of inference that has a possible token relative to that situation such that if performed would generate knowledge of the conclusion. Since some premise of a question-begging argument cannot be known in the situation it is advanced without first knowing the conclusion, question-begging arguments fail to display a type of inference that has a possible token relative to that situation such that if performed would generate knowledge of the conclusion. Question-begging arguments are defective, because they are not epistemically serious. Since the Twardowski argument as used in the above situation is epistemically serious, it does not beg the question according to Biro even if it fails to display the arguer's inference.

Biro's account of begging the question focuses on a justificatory use of arguments according to which they aim to show that that there are reasons to believe the conclusion, regardless of who believes these reasons. Let's call this sense of justification, impersonal justification, which is an expression I borrow from Sinnott-Armstrong and Fogelin (2010, p. 5). Biro implicitly appeals to the notion of a reason as a fact. For example, that it is raining is a reason for me to bring my umbrella when I go outside regardless of whether I believe that it is raining. The existence of the bylaw is a reason for anybody to believe the universal generalization that is the first premise of the Twardowski argument, regardless of who is aware of the bylaw. The argument in this situation succeeds in impersonally justifying its conclusion, whether or not anyone performs a token of the type of inference it displays. That the Twardowksi argument fails to display my inference is indeed irrelevant to whether it impersonally justifies its conclusion.

However, there are justificatory uses of arguments that target particular reasoners with the aim of demonstrating that some of their beliefs serve as good reasons for believing the conclusion. Arguer and audience justification are two such uses of arguments. As previously discussed, to determine whether arguments used in these ways succeed we must pay attention to the actual beliefs of target reasoners (i.e., arguer and audience, respectively). For example, the existence of the bylaw, unbeknownst to me, is irrelevant to whether the Twardowski argument successfully functions as an instrument of arguer justification. The argument fails to display an inference I perform regardless of the existence of the bylaw. Assuming that in the 
above situation the argument is used as an instrument of audience justification and that, say, its audience is agnostic about the conclusion and accepts the premises on the basis of my authority, again the existence of the bylaw is irrelevant to whether this use of the argument is successful.

The desideratum of a uniform account of question begging across the different justificatory uses of argument may not be attainable if, as seems to be the case, each justificatory use has unique criteria for success. This suggests that there might be different ways that an argument can beg the question depending on how it is used as an instrument of justification. In a given situation, an argument may beg the question relative to one justificatory use, but not relative to another. Whether an argument displays an inference every target reasoner can perform is relevant to whether it is good qua instrument of arguer or audience justification, but is irrelevant to its quality qua instrument of impersonal justification. Since an account of the justificatory uses of argument is prior to an account of begging the question, it is wrong to rule out the relevance of arguer and audience justificatory uses of an argument to whether it is used in a questionbegging way, because they escape one's account of begging the question. I find it implausible to claim that the Twardowski argument does not beg the question in the above situation merely because it works as impersonal justification of its conclusion. At the very least, we need to identify the justificatory function of the argument first and then assess whether it begs the question relative to that identification. For example, as previously noted, no propositionally circular argument will fulfill a justificatory function of an argument that requires that it display a type of inference. However, a propositionally circular argument can be used to justify belief in the conclusion by virtue of exemplifying the conclusion. In sum, an argument that displays a type of inference may be used in a situation so that it impersonally justifies its conclusion even though a target reasoner believes a premise because she believes the conclusion. Rather than conclude that an argument advanced as a statement of inference which fails to display an inference performable by every target reasoner is not sufficient for it to beg the question, I maintain that an argument can beg the question relative to one justificatory use but not relative to another.

There is criticism of making the assessment of whether an argument begs the question turn on the determination of why target reasoners believe or reject an unsupported premise. For example, Wilson (1988, p.44) argues that it frequently makes 
the assessment of question-begging difficult, because it can be hard to know why someone accepts or rejects an unsupported premise since there are many propositions that may serve as reasons for accepting or rejecting it. Also, Biro (1977, p. 263) claims that making it necessary to pin down the relevant beliefs of target reasoners introduces an extreme relativity into argument assessment that makes it impossible to assess an argument used in a given situation as absolutely begging the question. For example, an argument may be used in a situation according to which it begs the question relative to Smith who believes an unsupported premise because she believes the conclusion, but does not beg the question relative to Brown who does not. I now briefly respond to these two criticisms, starting with Wilson's.

I agree that in a given situation in which an argument is advanced as a statement of inference there are many propositions that may serve as reasons for accepting or rejecting an unsupported premise. However, I fail to see how this generates serious criticism of making the assessment of begging the question turn on the determination of target reasoners' basis for accepting unsupported premises. The difficulty of determining why someone accepts or rejects an unsupported premise is not insurmountable. As Ritola (2001, pp. 305-307) emphasizes in his response to Wilson, background knowledge of target reasoners' beliefs and knowledge of their beliefs externalized through the process of argumentation are what is at play in determining a target reasoner's basis for accepting an unsupported premise. Furthermore, any pragmatic account of begging the question such as Wilson's faces the difficulty of determining why someone accepts or rejects an unsupported premise in assessing whether a use of an argument commits the fallacy.

Wilson adopts the equivalence conception of circularity and maintains that a circular argument begs the question if in the context in which it is used it is ill-suited to fulfill the principal conversational purpose for which it is advanced (Wilson, 1988, p.50). Suppose that I advance what Wilson takes to be an equivalence-circular argument, say of the form, $p \& q / \therefore p$, for the benefit of a target reasoner R. Given that the conversational purpose of the argument is to state an inference performable by $\mathrm{R}$, the determination of R's basis for accepting the premise is relevant to knowing whether my use of the argument begs the question by the lights of Wilson's account. Therefore, Wilson does not avoid the difficulty of determining why someone accepts or rejects an unsupported premise (Ritola, 2001, p. 305, makes a similar point). 
My response to Biro is that relative to an audience of target reasoners an argument advanced as a statement of inference absolutely begs the question if it fails to display an inference that a target reasoner $\mathrm{R}$ can perform because R's reasons for accepting an unsupported premise include the conclusion or would have to include it in order for $\mathrm{R}$ to accept the conclusion. Therefore, an argument may absolutely beg the question, because it fails to display an inference performable by a proper subset of the audience of target reasoners. This is perfectly reasonable given the range of justificatory purposes an argument may serve. For example, if I advance an argument as an instrument of audience justification, then I invite every target reasoner to perform a token of the type of inference that the argument purports to display. The invitation fails and my use of the argument begs the question if the argument display an inference performable by only some of the target reasoners, because the conclusion serves as their reason to believe a premise. By begging the question, the justificatory purpose of the argument is not fulfilled, even though for some target reasoners belief in the premises may justify their belief in the conclusion. It is worth highlighting in responding to Biro that I follow those who maintain that it is not arguments, but uses of arguments that are potentially question begging (e.g., Sinnott-Armstrong, 1999, p. 177; Wilson, 1988, p. 51). Since, on my view, begging the question is a defect of the use of an argument as a statement of inference, that some target reasoner cannot perform an inference displayed by an argument so used suffices for it to (absolutely) beg the question regardless of the epistemological impact of the argument on other target reasoners.

\section{Conclusion}

Appealing to a causal view of inference, I have characterized a syntactic circularity condition that nullifies an argument's potential to display an inference performable by its target reasoners. This grounds my characterization of the fallacy of begging the question, which focuses on the use of arguments as statements of inference. A use of an argument as a statement of inference begs the question if the collection of premises, direct or otherwise, that some target reasoner would have to accept in order to accept the conclusion includes the conclusion. If this condition obtains, we may say that the argumentation is propositionally circular. The vice of a question-begging use of an argument, 
even if it succeeds to impersonally justify its conclusion, is that the argument does not display an inference that all its target reasoners can perform and thus fails as a statement of inference. This explains why an argument used in a question-begging way cannot serve those forms of justification that require it to display an inference performable by every target reasoner (e.g., arguer and audience forms of justification).

My characterization of question begging follows the literature and tradition in logic which says that the fallacy occurs only in argumentation that is circular (Walton, 2006, p. 244). However, I reject accounts of question begging that elucidate the relevant circularity condition in terms of a target reasoner's performance of a circular inference. After all, question-begging uses of arguments are possible, but circular inferences are not. For the purpose of clarifying begging the question, I join Woods and Walton (1975, p. 114) in urging reform of "argument" in the argumentation literature on begging the question so that the expression is not used to refer to inference and, more broadly, to reasoning.

\section{References}

Audi, R. (2011). Epistemology. Third edition. London: Routledge.

Biro, J. (1977). Rescuing 'Begging the Question'. Metaphilosophy 8, 257-271.

Biro, J. and H. Siegel (2006). In Defense of the Objective Epistemic Approach to Argumentation. Informal Logic 26, 91101.

Boghossian, P. (2012). What is inference? Philosophical Studies 169, 1-18.

Botting, D. (2011). Can 'Big' Questions be Begged? Argumentation 25, 23-36.

Fogelin, R. and W. Sinnott-Armstrong (2010). Understanding Arguments: An Introduction to Informal Logic, $8^{\text {th }}$ ed. Harcourt Brace College Publishers

Harman, G. (1973). Thought. Princeton: Princeton UP.

Harman, G. (1986). Change in View. Cambridge, MA: MIT Press.

Hazlett, A. (2006). Epistemic Conceptions of Begging the Question. Erkenntnis 65, 343-363.

Jackson, F. (1987). Conditionals. Oxford: Basil Blackwell. 
Jacquette, D. (1993). Logical Dimensions of Question-Begging Argument. American Philosophical Quarterly 30, 317-327.

Lippert-Rasmussen, K. (2001). Are Question-Begging Arguments Necessarily Unreasonable? Philosophical Studies 104, 124-141.

McKeon, M. (2013). On the Rationale for Distinguishing Arguments from Explanations. Argumentation 27, 283-303.

Pinto, R. (2001). The Relation of Argument to Inference. In Argument, Inference and Dialectic (pp. 32-45, Ch. 4), Dordrecht, Holland: Kluwer Academic Publishers.

Ritola, J. (2001). Wilson on Circular Arguments. Argumentation $15,295-312$.

Ritola, J. (2003). Begging the Question: A Case Study. Argumentation 17, 1-19.

Sanford, D. (1981). Superfluous Information, Epistemic Conditions of Inference, and Begging the Question. Metaphilosophy 12, 145-158.

Sanford, D. (1988). Begging the Question as Involving Actual Belief and Inconceivable Without it. Metaphilosophy 19, 3237.

Salmon, W. (1984). Logic. Englewood Cliffs, NJ: Prentice Hall, Inc.

Sinnott-Armstrong, W. 1999. Begging the Question. Australasian Journal of Philosophy 77, 174-191.

Sorenson, R. (1991). 'P, Therefore P' Without Circularity. Journal of Philosophy 88, 245-266.

Walton, D. (1990). What is Reasoning? What is Argument?" Journal of Philosophy 87, 399-419.

Walton, D. (1994). Begging the Question as a Pragmatic Fallacy. Synthese 100, 95-131.

Walton, D. (2006). Epistemic and Dialectical Models of Begging the Question. Synthese 152, 237-284.

Wilson, K. (1988). Circular Arguments. Metaphilosophy 19, 3852.

Woods, J. and D. Walton (1975). Petitio Principii. Synthese 31, 107-127.

Woods, J., A. Irvine, and D. Walton (2004). Argument: Critical Thinking, Logic, and the Fallacies. Toronto: Pearson/Prentice Hall.

Woods, J. (2008). Begging the question is not a fallacy. In: C. Dégremont, L. Keiff, and H. Rükert (Eds.), Dialogues, Logics and Other Strange Things: Essays in Honour of Shahid Rahman (pp. 523-544), London: College Publications. 